\title{
COLLAPSE OF THE LUNG ASSOCIATED WITH PRIMARY TUBERCULOSIS: A REVIEW OF 51 CASES
}

\author{
BY
}

\author{
A. MARGARET C. MACPHERSON, P. A. ZORAB, AND LYNNE REID \\ From the Children's Contact Clinics of the Brompton Hospital, London
}

(RECEIVED FOR PUBLICATION APRIL 21, 1960)

In 1950, a review of 39 cases of collapse of the lung associated with primary pulmonary tuberculosis was published (Macpherson and Lutwyche, 1950). The present work is based on a further study of these patients, with the addition of 12 others.

These 51 patients showed radiological evidence of segmental or lobar lesions suggesting a reduction in lung volume, and they were all selected from the 1,323 patients attending the Brompton Hospital contact clinics between 1932 and 1957 who had positive tuberculin tests. Those with pulmonary shadows without reduction in lung volume had been excluded. In 40, hilar glands were visible, indicating that tuberculous infection had taken place recently; in 11 , glandular enlargement was not evident though the parenchymatous lesions still remained.

In all the original 39 patients the pulmonary lesions had occurred during the early stage of a primary tuberculous infection and were usually associated with demonstrable hilar gland enlargement. Our additional ones include some in whom the acute stage had passed at the time the patient was first seen, and the pulmonary lesions had been present for several months. The original 39 have now been followed up for a further 10 years. Two patients could not be traced, in some it has been necessary to rely on postal inquiries, while the remainder have been followed up over a period from 1934 to the present time. The majority have been seen at regular intervals, varying from one and a half to 26 years, and 10 patients have attended over a period of 20 years, the average follow-up period being 12 years.

Pathological interpretations have not been attempted from radiological or clinical observations, but pathological evidence is available from seven patients in whom the affected part of the lung was removed.

The present work is not primarily a statistical study, since one is already in progress at the
Brompton Hospital as part of a full review of all the children attending the hospital's children's contact clinics between 1932 and 1953. The particular concern of this report is to follow the clinical course which our patients have taken, so that some guide can be given in making a prognosis, and to consider how the findings should influence our treatment of these patients in the early stage of the disease.

\section{MANAGEMENT}

The majority of children in this series had contracted tuberculosis before the advent of chemotherapy, but the treated cases are too few for any safe deductions to be made as to its value. There are several reports (Cameron, Hay, and Temple, 1957 ; Bentley, Grzybowski, and Benjamin, 1954 ; Lincoln, Harris, Bovornkitti, and Carretero, 1958) suggesting that the drugs have small effect on the rate of healing of either the hilar glands or of associated endobronchitis. This is not surprising in view of the amount of caseous material found in the affected glands. Nevertheless, most of the children in this series who have been seen since 1949 were given chemotherapy if there was evidence of active tuberculous disease. A combination of streptomycin, P.A.S., or isoniazid was used, primarily to prevent extrapulmonary complications but also in the hope that it might promote healing within the lungs or bronchi.

Many of the children received institutional treatment. The value of this in severely affected cases is obvious. Its value is less obvious in mild cases and in children who can be well cared for at home. Most physicians, however, agree that when a primary tuberculous affection is severe enough to cause a segmental lesion, a period of rest and observation is beneficial and this is often carried out most satisfactorily in an institution. It is noteworthy that of the 15 children whose chest radiographs cleared, only one child was treated at 
home and 14 in hospital, whereas of the 36 children whose radiographs never returned to normal over one-third (14) had been treated at home during the active stages of the disease. During 1939-45 there was often no alternative to home treatment and before this there was a shortage of suitable beds in institutions.

When they were first seen, 46 of the 51 children in this series were in the early stage of a primary tuberculous infection, 40 of them having demonstrable hilar gland enlargement. Five had passed through this early stage, and the pulmonary lesions showed little subsequent radiographic change. Assessment from plain radiographs of the time taken for segmental or lobar lesions to clear is bound to be approximate. Indeed, some authors have thought it to be too inconclusive to be worth while (Lincoln et al., 1958). We have, nevertheless, thought an assessment worth attempting, though there were several difficulties. For example, a collapsed segment or lobe may not completely re-expand and it is difficult to decide when the maximum re-expansion has occurred. Further, it may not be easy to say which of serial radiographs, not always strictly comparable, is the first to show complete clearing. We have regarded as normal any radiograph which would have excited no comment if examined for the first time without knowledge of the case. Radiographic clearing does not necessarily imply that the underlying lung is histologically normal. In 17 instances out of the 59 lesions which occurred in 51 children, complete radiographic clearing of the pulmonary lesions had occurred within six months from the time they were first diagnosed. After a further six months another seven had cleared, making a total of 24 during the first year. After this the rate of clearing was considerably slower, and complete clearing occurred in only six more cases during the second year after the lesions were first diagnosed.

Bronchography will frequently demonstrate abnormalities if performed during the early stages of primary tuberculosis when hilar gland enlargement is present. We may find alteration of the normal outline of the trachea or the major bronchi as the result either of external compression or ulceration through the bronchial wall. A collapsed lobe or segment may not fill, or the bronchi which have filled in a collapsed area may show " crowding." Amongst the children in the series reported by Lincoln et al. (1958), two-thirds of 103 cases of tuberculous endobronchial disease proved at bronchoscopy were subsequently found to have abnormal bronchograms.
We did not perform bronchography as a routine because the procedure in children needs to be performed under a general anaesthetic, and infected material may be spread to healthy parts of the lungs. Bronchography was therefore either not performed or was deferred until later. When the child has passed through the active stages of the primary infection, especially if there are residual symptoms and physical signs, a bronchogram may be very helpful in localizing the residual damage and in showing its extent. Twenty-nine of the children in this series required bronchography.

\section{RESULTS}

Our patients have been grouped in the following way:

Group 1.-Those in whom there was complete clinical and radiographic recovery.

Group 2.-Those in whom there was complete clinical but incomplete radiographic recovery, i.e., there were residual shadows indicating a persisting reduction in lung volume.

Group 3.-Those in whom recovery from the initial tuberculous infection occurred but in whom symptoms persisted and were accompanied by radiographic abnormalities.

Age Distribution.-The age distribution of the 51 children in this series is shown in Table $I$.

TABLE I

AGE DISTRIBUTION

\begin{tabular}{|c|c|c|c|c|}
\hline $\begin{array}{l}\text { Age when Lesion } \\
\text { was First Noted }\end{array}$ & Group 1 & Group 2 & Group 3 & Total \\
\hline 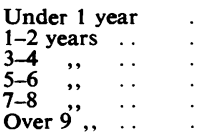 & $\begin{array}{l}0 \\
4 \\
5 \\
3 \\
3 \\
0\end{array}$ & $\begin{array}{l}0 \\
6 \\
5 \\
6 \\
4 \\
5\end{array}$ & $\begin{array}{l}1 \\
0 \\
4 \\
1 \\
2 \\
2\end{array}$ & $\begin{array}{r}1 \\
10 \\
14 \\
10 \\
9 \\
7\end{array}$ \\
\hline Total & 15 & 26 & 10 & 51 \\
\hline
\end{tabular}

Thirty-four out of the total of 51 children were between 1 and 6 years of age. Only one child was under 1 year old, but it should not be deduced from this fact that tuberculous lesions of this kind are uncommon at this age. In the 25 -year period under review only 34 of the children attending the clinic were less than 1 year old, at which age they are more commonly referred to paediatric hospitals for the investigation and treatment of chest conditions.

Localization of Lesions.-A total of 59 segmental or lobar lesions occurred in the 51 


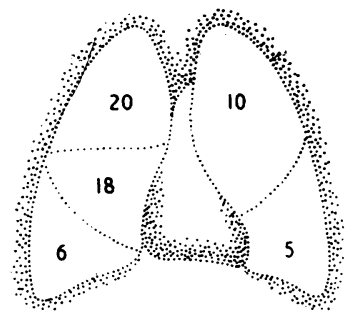

INITIAL LESIONS

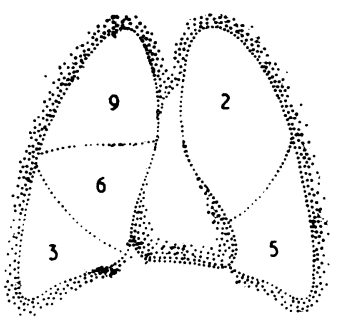

PERSISTING LESIONS
FIG. 1.-Distribution of lesions in 51 children.

children, and of these 25 persisted. Their distribution within the lobes is shown in Fig. 1.

The initial lesions have also been grouped as shown in Table II.

TABLE II

GROUPING OF INITIAL LESIONS

\begin{tabular}{|c|c|c|c|c|}
\hline Site & Group 1 & Group 2 & Group 3 & Total \\
\hline $\begin{array}{l}\text { Right upper lobe } \\
\quad, \quad \text { middle lobe } \\
\text { Left upper lobe } \\
\text { Lingula } \\
\text { Left lower lobe }\end{array}$ & $\begin{array}{l}7 \\
4 \\
1 \\
5 \\
1 \\
0\end{array}$ & $\begin{array}{r}11 \\
11 \\
2 \\
3 \\
1 \\
0\end{array}$ & $\begin{array}{l}2 \\
3 \\
3 \\
0 \\
0 \\
5\end{array}$ & $\begin{array}{r}20 \\
18 \\
6 \\
8 \\
2 \\
5\end{array}$ \\
\hline Total & 18 & 28 & 13 & 59 \\
\hline
\end{tabular}

In the distribution of the lesions the right upper lobe, or one of its segments, was the site in which lesions were found most commonly. Next in order was the right middle lobe. The lower lobes were less commonly affected; nevertheless, the prognosis for lower lobe lesions is not good, for it will be seen that of 13 lower lobe lesions only five showed recovery. With the poor drainage and consequent secondary infection in these sites symptoms were common and troublesome. In five children surgical treatment was required for relief of the symptoms resulting from lower lobe lesions.

BRONCHOSCOPY.-We think that abnormal findings would be present in a high proportion of patients if bronchoscopy had been performed as a routine. However, bronchoscopy in small children requires a general anaesthetic, and, since this is not without risk, it was used only when likely to reveal information of value in treatment. By adopting this conservative attitude, unnecessary bronchoscopies were avoided in 15 children, that is, all those in Group 1. The value of aspiration at bronchoscopy as a therapeutic measure has been emphasized by Görgényi-Göttche and Kassay in 1947 and by Cameron et al. in 1957, the latter obtaining clearing of lung shadows in five out of 27 patients following repeated bronchoscopic aspirations. In these five patients no residual collapse or bronchiectasis was found. While opening up the lumen of an infected bronchus may result in re-aeration of the lung beyond, this may not necessarily be of advantage if, thereby, tubercle bacilli from the discharging gland or tuberculous ulcer in the bronchus are aspirated into the re-aerated segment. In our own series too few bronchoscopic examinations were performed to form any final conclusions. Details are given in Table III.

TABLE III

BRONCHOSCOPIC FINDINGS IN 12 CHILDREN AT TIME OF INITIAL INVESTIGATIONS

\begin{tabular}{|c|c|c|c|}
\hline Case & Group & Site of Lesion & Findings \\
\hline 1 & 2 & R. middle lobe & $\begin{array}{l}\text { Collapsed R.M.L. orifice. Yellowish } \\
\text { nodule projecting into lumen } \\
\text { below mid lobe on ifice }\end{array}$ \\
\hline 2 & 2 & $\therefore$ & $\begin{array}{l}\text { R. main bronchus narrowed. Small } \\
\text { polypoid granulation tissue bleed- } \\
\text { ing easily on touch seen above } R \text {. } \\
\text { middle lobe orifice }\end{array}$ \\
\hline 3 & 2 & ,. & $\begin{array}{l}\text { Right mid lobe bronchus funnel- } \\
\text { shaped. No ulceration was seen }\end{array}$ \\
\hline 4 & 2 & L. upper lobe & $\begin{array}{l}\text { Nodule and whitish material seen } \\
\text { protruding from front wall of } L \text {. } \\
\text { main bronchus. Bulging of lateral } \\
\text { aspect of } L \text {. main bronchus }\end{array}$ \\
\hline 5 & 2 & , & $\begin{array}{l}\text { Caseating gland parially obstructing } \\
\text { left upper lobe bronchus }\end{array}$ \\
\hline 6 & 2 & R. middle lobe & $\begin{array}{l}\text { Narrowed right mid lobe bronchus } \\
\text { probably from fibrous stricture or } \\
\text { pressure of glands }\end{array}$ \\
\hline 7 & 2 & , & $\begin{array}{l}\text { Right mid lobe bronchus red, very } \\
\text { much stenosed, polypoid mass } \\
\text { protruding into it }\end{array}$ \\
\hline 8 & 3 & L. lower lobe & $\begin{array}{l}\text { Narrowed right mid lobe bronchus } \\
\text { and } L \text {. main and } L \text {. upper lobe } \\
\text { bronchi }\end{array}$ \\
\hline 9 & 3 & $\begin{array}{l}\text { R. middle lobe } \\
\text { R. upper lobe }\end{array}$ & $\begin{array}{l}\text { Stenosis of } R \text {. intermediate stem } \\
\text { bronchus immediately below } R \text {. } \\
\text { upper lobe orifice }\end{array}$ \\
\hline 10 & 3 & , & $\begin{array}{l}\text { Complete gland projection into } R \text {. } \\
\text { main bronchus }\end{array}$ \\
\hline 11 & 3 & , & $\begin{array}{l}\text { Obstructive emphysema R. lower } \\
\text { lobe, partial stenosis R. main } \\
\text { bronchus, bronchiectasis of apical } \\
\text { segment of R. lower lobe }\end{array}$ \\
\hline 12 & 3 & L. lower lobe & $\begin{array}{l}\text { L. lower lobe bronchus compressed } \\
\text { obliquely, opening on inspiration } \\
\text { and discharging frothy secretions; } \\
\text { the mucosa congested but not } \\
\text { ulcerated }\end{array}$ \\
\hline
\end{tabular}

\section{RESECtion Material}

Seven patients required resection of one or more lobes of the lungs (Table IV). The earliest of these operations was performed in 1938 and neither the resected specimen nor the detailed report could be traced. Sections from the remaining six and the original macroscopic report of the specimens have been re-examined. It will be seen that in five of the seven children resection was performed for post-tuberculous bronchiectasis. The interval between first diagnosis of pulmonary 
TABLE IV

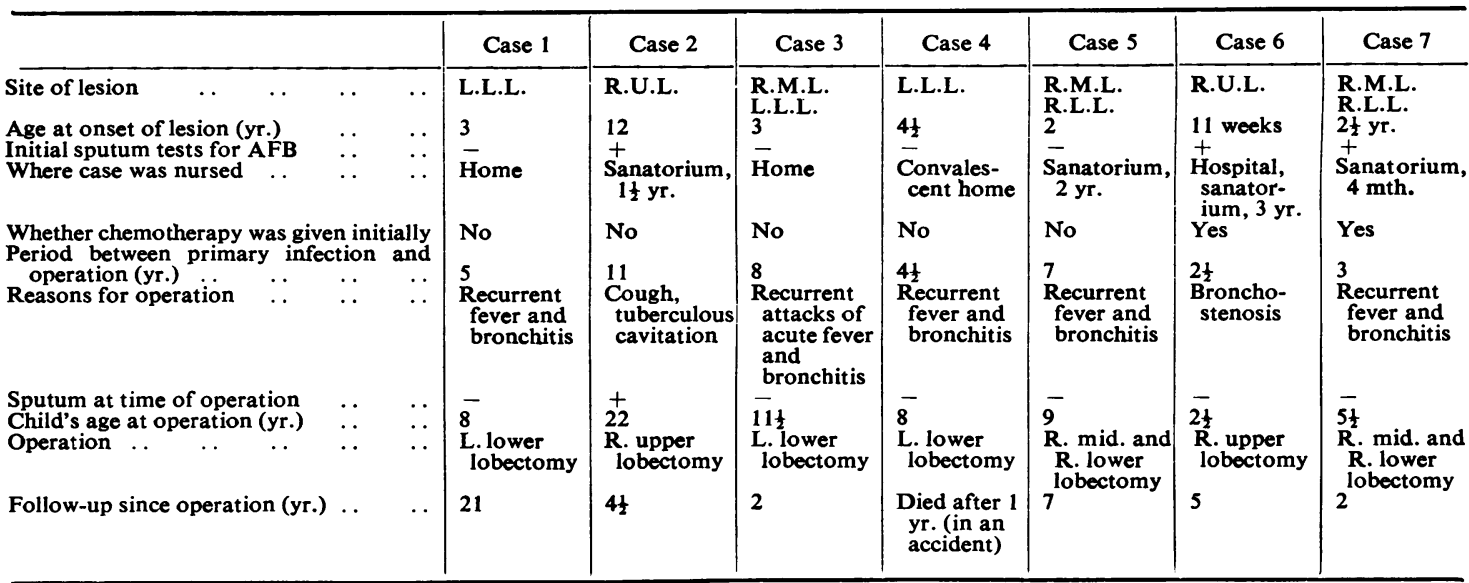

collapse and the time of operation varied from one year to 11 years, the mean being five and a half years. The appearance most often seen on microscopic examination of the peripheral part of the lung is that of the circulatory changes characteristic of chronic collapse, which is discussed later.

\section{Case Reports}

CASE 1.-Primary tuberculosis was diagnosed in 1937 when the patient was 3 years old. No chemotherapy was given. After the primary complex had healed the child continued to have a cough and sputum. Bronchography (1938) showed collapse of the left lower lobe with bronchiectasis of all the branches. Bronchoscopy was not performed. At operation

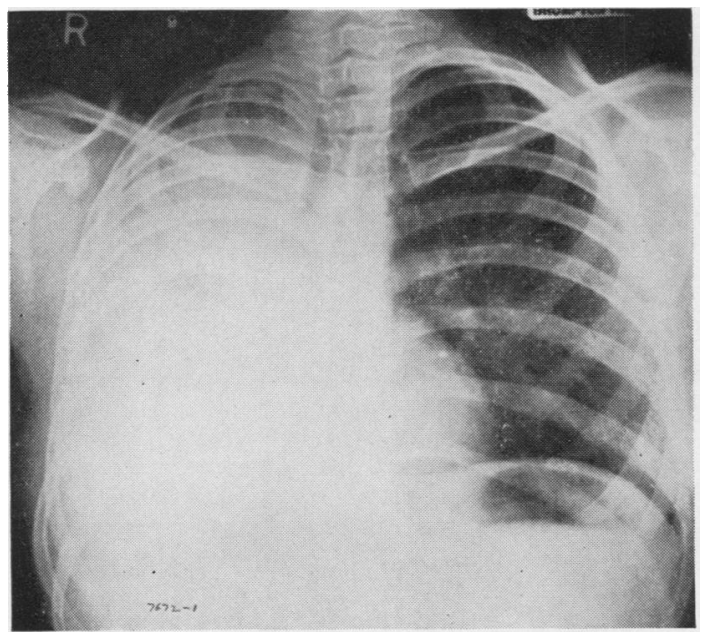

FIG. 2a.-S.D. Chest radiograph on June 8, 1944, showing massive collapse of right lung.
(1938), one year after primary tuberculosis had been first diagnosed, the left lower lobe was found to be collapsed but free of adhesions and was removed.

The sections and the report made upon them could not be traced.

Twenty-one years later the patient is very well and has no symptoms.

CASE 2.-Severe pulmonary collapse (Fig. 2a) associated with a tuberculous pleural effusion occurred in 1944 when the patient was 12 years old. Chemotherapy was not available. The right main bronchus was occluded by a gland which, on bronchoscopy, was seen to be almost completely extruded into it. After this particularly severe primary tuberculous infection had healed, the child was left with a collapsed right upper lobe (Fig. $2 b$ and $2 c$ ).

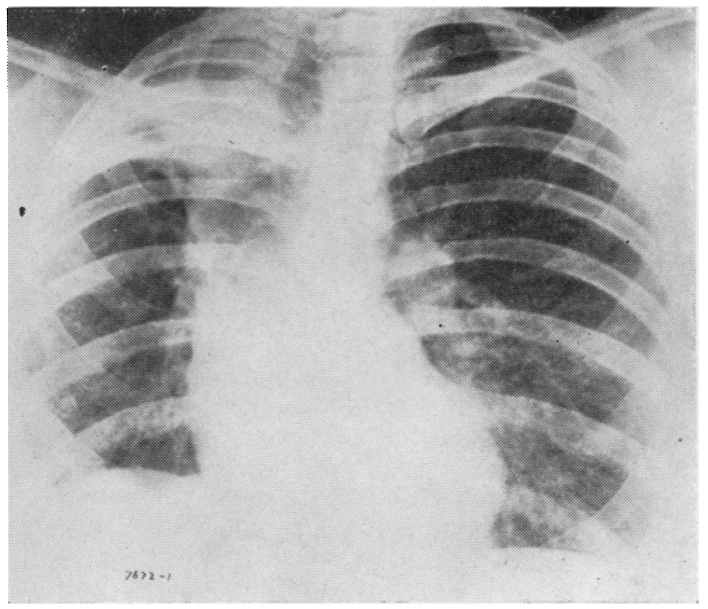

FIG. 2b.-S.D. Chest radiograph on February 8, 1954. showing chronic right upper lobe collapse. 


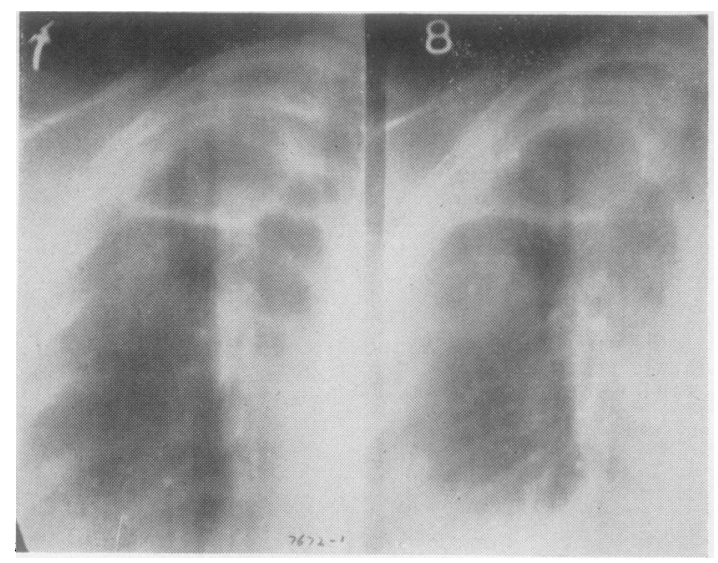

FIG. 2c.-Tomograph on August 24, 1954, showing right upper lobe cavitation.

Eleven years later (1955) cavitation occurred in this lobe and the sputum yielded $M$. tuberculosis. The breakdown had occurred between two visits to the Out-patient Department at three-monthly intervals. Bronchography (1955) now showed bronchiectasis involving all three segments of the right upper lobe, and bronchoscopy before operation (1955) showed reddening of the bronchial mucosa but no other abnormality. At operation, a right upper lobectomy was performed. The right upper lobe was small and contained a thick-walled cavity $4 \mathrm{~cm}$. by $2 \mathrm{~cm}$. The niddle lobe, which was not removed, had already expanded upwards, was large and some tubercles were seen on its surface.

Fig. $2 d$ is the radiograph taken two years after right upper lobectomy.

Microscopic sections of the right upper lobe showed chronic collapse. The cavity was lined by caseous material and throughout the lobe there were collections of caseous material surrounded by tuberculous granulation tissue.

This was the only child in the series who subsequently developed active pulmonary tuberculosis. The tuberculous cavity had occurred in a collapsed right upper lobe caused by the primary tuberculous infection.

CASE 3.-Primary tuberculosis attacked this child in 1949 when she was $2 \frac{1}{2}$ years old.

Bronchoscopy one year later revealed a slit-like opening in the left lower lobe bronchus which closed completely on expiration (Fig. 3a). No granulation tissue was seen on the left but was present near the right mid-lobe orifice. Tuberculous osteomyelitis of the pubic bone occurred at this time but subsided after immobilization. No chemotherapy was given. After the primary tuberculous infection had healed the child remained well for five years, but then developed severe bronchitis which recurred frequently and interfered considerably with her normal life.

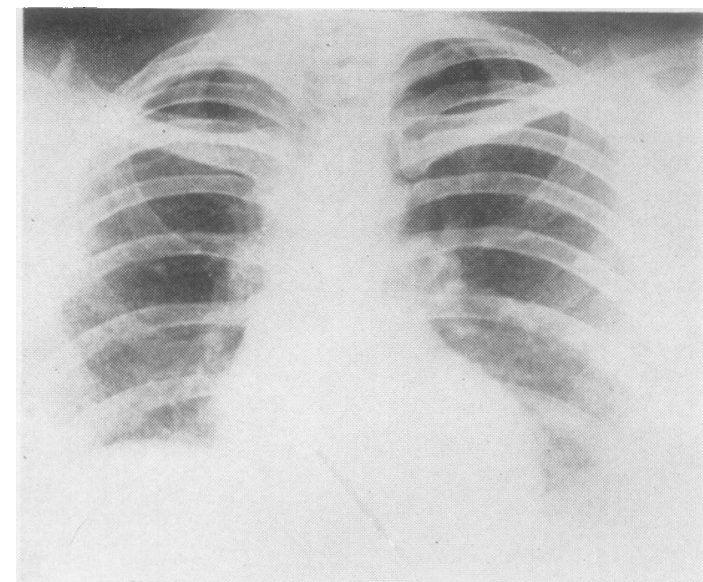

FIG. 2d.-Chest radiograph on January 5, 1959, two yeats afier right upper lobectomy.

Bronchography in 1957 (Fig. 3b), when she was 12 years old, showed narrowing of the distal part of the left main bronchus and total collapse of the left lower lobe. Bronchoscopy showed stenosis of the left lower lobe bronchus and healed ulceration in the wall of the right main bronchus. At operation at the age of 12 years (nine years after collapse was diagnosed), the left upper lobe was found to be filling the greater part of the left side of the chest. The left lower lobe was very small and was removed. There were a number of thin vascular adhesions. The obstructed bronchial tree contained thick pus.

Histological examination of a section of the whole of the left lower lobe showed massive collapse (Fig. 3a).

CASE 4.-Collapse associated with primary tuberculosis was diagnosed in 1949 when the child was $4 \frac{1}{2}$ years old. No chemotherapy was given. When the primary infection had healed the child continued to have a cough, sputum, and recurrent bouts of fever.

Bronchography (1949) showed crowding of the left basal bronchi with dilatation of the branches to anterior and lateral basal segments. The apical segment of the left lower lobe was normal. When repeated two and a half years later (1952) bronchography showed partial re-aeration of the lobe with dilatation of the anterior and lateral basal segments. the posterior basal segments being normal and the lateral basal segmental bronchi spread more widely but not dilated. Bronchoscopy during initial investigations in 1949 revealed a left lower lobe bronchus which was compressed obliquely and which, on inspiration, opened and discharged frothy secretions.

A left lower lobectomy was performed in 1953 when the child was 8 years old, four years after collapse was diagnosed. At operation the left lower lobe was small and there was considerable peribronchial and perivascular fibrosis throughout. A good initial result 


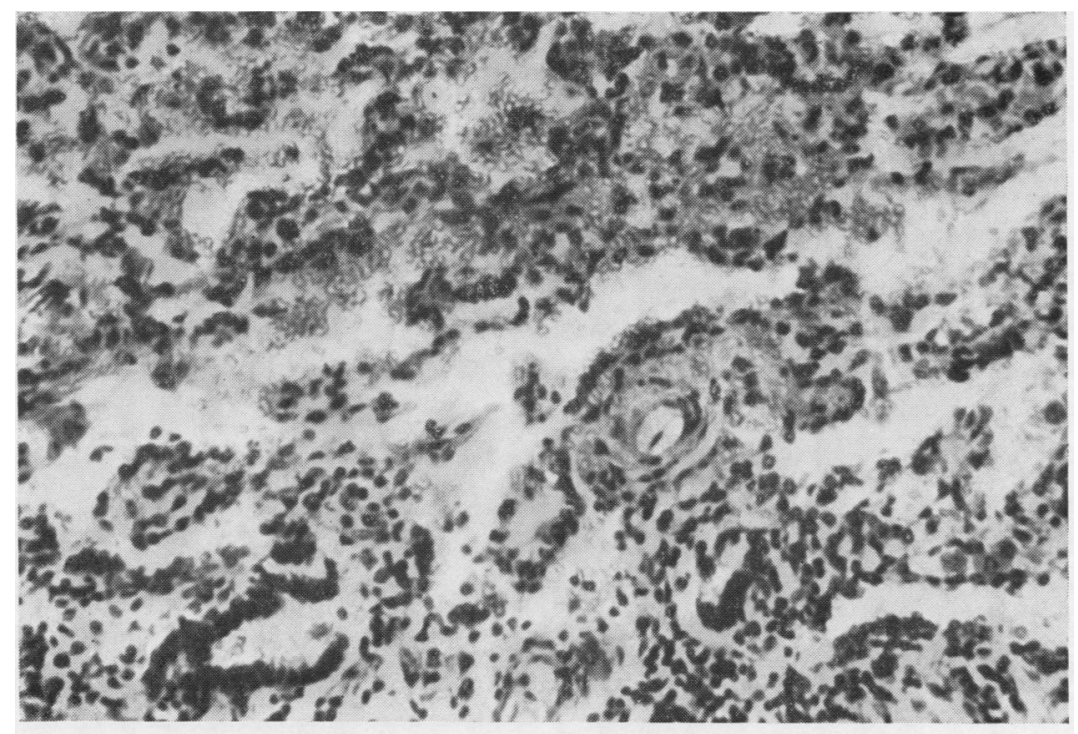

FIG. 3a.-Microscopic section taken from Case 3 (R.S.) showing chronic collapse with large numbers of red blood cells in spaces resembling sinusoids.

FIG. 3b.-R.S. Chest radiograph on September 21, 1949, showing collapse of left lower lobe and right middle lobe.

FIG. 3c.-R.S. Tomogram on August 7, 1951, showing collapse of left lower lobe.

FIG. 3d.-R.S. Bronchogram on August 21, 1957, showing almost complete stenosis and non-filling of left lower lobe bronchus.

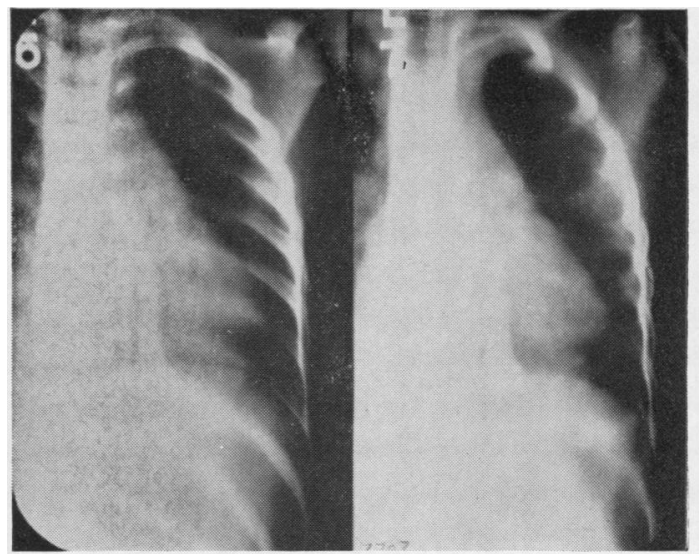

FIG. $3 c$

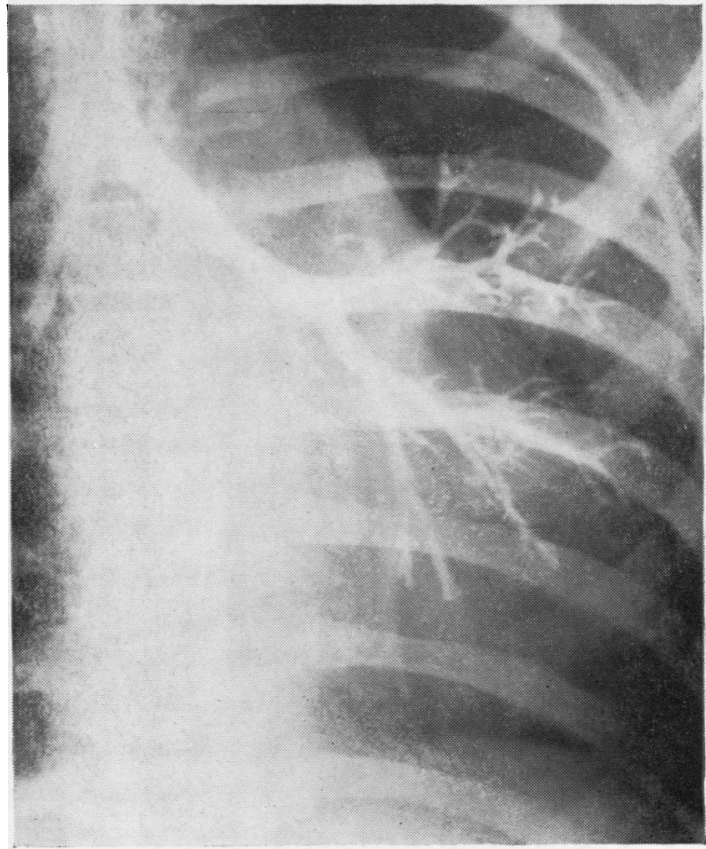


was obtained; the child died in a road accident one year later.

The microscopic section from the left lower lobe showed bronchi dilated proximally but obliterated by scar tissue at the fourth or fifth generation. Between the bronchial pathways the lung was still aerated and there was no evidence of pulmonary collapse. It may be that originally the whole lobe was collapsed and only the bronchial pathways in the anterior and middle basal segments had been obliterated by infection. Expansion in these areas had probably occurred by collateral ventilation as described by Van Allen and Jung (1931).

CASE 5.-Primary tuberculosis with pulmonary collapse was diagnosed in 1945 when the child was 2 years old. Chemotherapy was not available. Recovery was incomplete and the child still had a persistent productive cough. Bronchography in 1952 showed stenosis of the right intermediate stem bronchus just distal to the upper lobe bronchus and bronchiectasis of the right middle and lower lobes, and bronchoscopy before operation showed a right intermediate stem bronchus narrowed to $1 \mathrm{~mm}$. from fibrous concentric stenosis. At operation (1952), seven years after collapse, it was found that the right middle and lower lobes were diminutive, the right upper lobe occupying most of the right chest.

Microscopic sections showed chronic massive collapse of the right middle and lower lobes. The bronchi in the affected areas showed considerable fibrosis.

CASE 6.-The onset of collapse associated with primary tuberculosis was diagnosed in 1952 when the baby was 11 weeks old. Chemotherapy was given. A discharging tuberculous sinus developed above the right clavicle. The right upper lobe collapsed and there was much wheezing due to obstructive emphysema of the right middle and lower lobes.

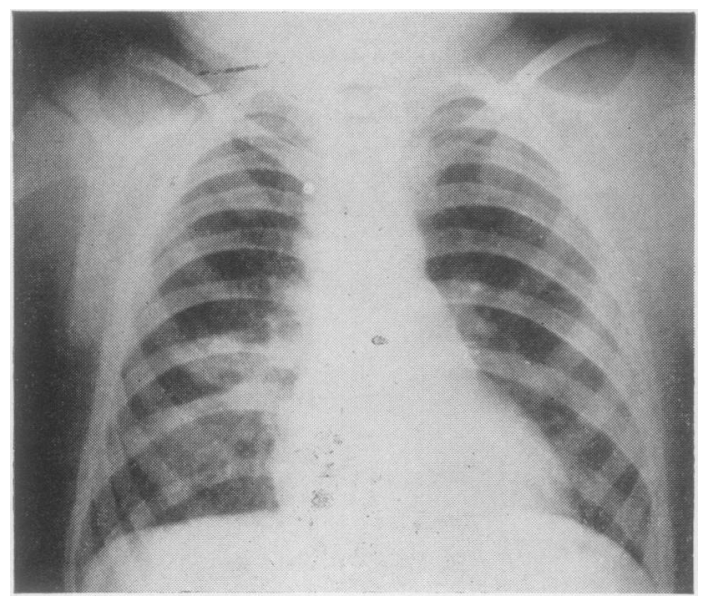

FIG. 4a.-C.M. Chest radiograph on January 1, 1955, showing lesions in tight lung (actually right middle and right lower lobe).
Bronchography in 1954 showed stenosis of the right main bronchus below the origin of the upper lobe, the anterior segment of the right upper lobe failed to fill, and in the apical segment of the right lower lobe bronchiectasis was seen. Bronchoscopy showed an abrupt stenosis just below the right upper lobe bronchus, the lumen being $1 \mathrm{~mm}$. by $2 \mathrm{~mm}$. No evidence of active ulceration was seen.

At operation (1954) the pleura over the right upper lobe was found to be adherent to the chest wall, especially anteriorly, and contained small nodules of tuberculous disease. The middle and lower lobes felt normal. The hilar structures were densely adherent, particularly the artery and bronchus, but the hilar glands were not enlarged. After the right upper lobe had been removed, the orifice of the right upper lobe bronchus was seen to be very small and the wall of the main bronchus was thickened. On probing, the main bronchus was found to be stenosed just below the upper lobe orifice. The stricture was resected and a large caseous gland removed from behind the right main bronchus, another being removed from above the azygos vein posteriorly. End-to-end anastomosis of the bronchus was then performed.

On histological examination the lung tissue was congested, suggesting early circulatory stages of collapse. The vascular changes were not as striking as those seen when resection was performed much later after collapse.

CASE 7.-The right middle lobe collapsed, associated with primary tuberculosis, in October, 1954, when the child was $2 \frac{1}{2}$ years old. Chemotherapy was given. The primary tuberculous lesion healed, but the child had recurrent attacks of severe fever and bronchitis, and bronchography in 1957 showed bronchiectasis in the apical segment of the right lower and right middle lobes and narrowing of the right main bronchus. Bronchoscopy showed the right main bronchus to be narrowed to half its normal size. At operation (1957),

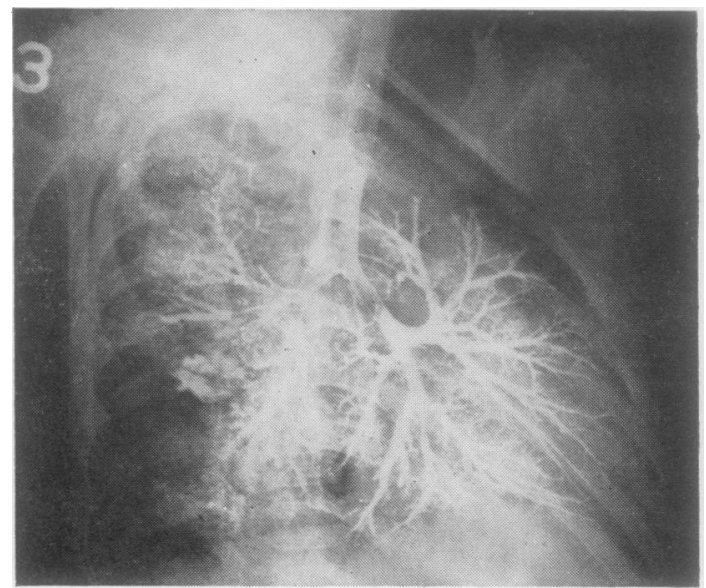

FIG. 4b.-C.M. Bronchogram on April 11, 1957, showing bronchiectasis. 
three years after collapse, the right middle and lower lobes, which were both removed, were found to be small and there were calcified glands at the hilum. There were a few pleural adhesions.

Histological examination showed a moderate degree of bronchial dilatation and the lung substance showed circulatory changes suggesting chronic collapse. No tuberculous lesions were found.

\section{Discussion}

The nature of lung shadows which are seen during the course of primary pulmonary tuberculosis in children has given rise to much discussion. Numerous and varied opinions have been expressed and these have been summarized by Jacobs (1958). Samuel Gee (1877) considered the lesions to be due to a caseous pneumonia, and Oppenheimer (1935) reproduced them by the intratracheal injection of sterile caseous material into hypersensitized rabbits. Morlock and Pinchin (1933) believed them to be due to the pressure of hilar glands causing absorption collapse, a view shared by Hutchison (1949): the last view is also supported by Brock, Cann, and Dickinson (1937) in their review of eight cases of tuberculous mediastinal lymphadenitis in childhood, and by Roberts and Blair (1950). Jones, Rafferty, and Willis (1942) quoted convincing evidence that the shadows may be due to a lobar or lobular atelectasis occurring as a result of interference with pulmonary aeration and drainage. Kent (1942) also supported this view. Seal (1958), working on material removed early in the disease, attributed the shadows to a non-caseating pneumonia, and wrote that " in Sully Hospital we have never encountered simple collapse as a cause of segmental radiological opacities that persist for a month or more." The most complete review of this whole question is that by Rich (1951). In this he quoted convincing evidence from several authors to show that either a resolving tuberculous pneumonia or atelectasis from the pressure of hilar glands may cause the segmental radiographic shadows described by Eliasberg and Neuland (1920) as epituberculosis. It is hardly profitable, therefore, to insist that either one or other is the sole cause for these appearances, since either or both may be present. The predominant changes found in any series of cases depend upon several factors, such as the age of the patient, the exact conditions for which admission to hospital was required, or at what stage resection was performed.

Collapse or consolidation of lung in this series of 51 cases occurred during the active phase of the primary lesion. Pulmonary lesions are more likely to develop in younger children than in those of the older age groups. Twenty-five instances occurred in children under 5 years and only seven after the age of 9 .

The majority of these children had few symptoms, the lesion only being found when the child was radiographed because of contact with a known case of tuberculosis. Some children, however, seem to develop a secondary infection at an early stage and are more ill, the clinical picture being that of bronchopneumonia. A few present with dyspnoea or stridor as a result of occlusion of a main bronchus or pressure on the trachea, and these may require urgent treatment.

In most patients the immediate effect of the pulmonary lesion may not be significant, but what has concerned us particularly are the late results. In the majority the results are good, with clearing of the radiographic shadows in 24 of the 51 within one year of their first visit and, in another six, within two years. Only one child subsequently developed pulmonary tuberculosis with cavity formation and that was at the age of 22 years; the girl had a severe primary lesion at the age of 12 years. Seven children (including the one with a tuberculous cavity) had persisting or recurrent symptoms resulting from collapsed lobes which required lobectomy.

Pathological Diagnosis of Chronic Collapse. -A lobe which has been collapsed for some years is small and on section dark red in colour, firm in consistency like a normal spleen. Often there are no adhesions. The fate of the different parts of the bronchial tree is characteristic. By reason of the large amount of cartilage in their walls and the inherent rigidity which this confers (Hayward and Reid, 1952), the proximal large bronchi are patent, perhaps dilated, with somewhat irregular walls; these fill on bronchography. The more peripheral bronchi, together with the bronchioles and alveoli, have collapsed, their walls in apposition. Although in the early stages the lung may reinflate, over the years the collapse becomes irreversible and associated with circulatory changes. Both in the acute and chronic phases the peripheral part fails to fill at bronchography.

Microscopically also the appearance is not unlike that of spleen: large numbers of red cells in spaces, resembling sinusoids, and with walls of nucleated cells but little fibrous tissue. The connective tissue septa are thickened and in some parts the area of lung in between is so small that the alveoli must have been absorbed into them.

The significance of this appearance has been elucidated by the studies of Adams, Hrdina, and Dostal (1935) of the change in the lungs in experimental animals which were killed at intervals during 18 months after collapse was induced by 
occlusion of a bronchus. Within a few days the alveolar spaces were collapsed, the capillaries in the walls dilated and tortuous. Gradually, over several months, areas appeared like large spaces filled with apparently normal blood, with walls of which the cellular detail was indistinct. Although fibrous tissue increased a little, the architecture of the lung could still be distinguished and was never erased by fibrosis. Little free iron was seen.

In the human lung the appearance is similar, suggesting that, as the air is absorbed following obstruction, the capillaries in the walls dilate and the alveolar walls come together and ultimately fuse, obliterating alveolar spaces so that the bulk of the reduced lung is no longer alveolar space, but the dilated capillaries within alveolar wall. A collapsed lobe, therefore, appears congested although the circulation may be reduced.

The pattern of lung is maintained, but it would seem that alveolar walls are gradually incorporated into the connective tissue of the septa and the sheaths of blood vessels and bronchi. Over the years the amount of alveolar remnant gradually diminishes, but there is some increase in fibrous tissue in the sites at which it occurs naturally. This is in contrast to the diffuse fibrosis, with destruction of tissue and loss of lung pattern, which typifies reduction in volume associated with scars of tuberculous pneumonia.

Of the resected specimens, that from the lung of the girl with active tuberculosis revealed a cavity and caseous foci in the otherwise collapsed lobe, while in none of the others were caseous lesions found. In four children the findings were characteristic of chronic collapse and in one the bronchi in some of the segments were dilated proximally and obliterated peripherally, probably as a result of secondary infection. The records of the other were not available. Thus in five children no caseous lesions were found, suggesting that in most the complications were due to collapse and not due to pneumonic change.

The majority of children with active primary lesions associated with radiographic changes suggesting a reduction in lung volume recover clinically; active tuberculous pulmonary lesions rarely develop. The policy of using general medical and antituberculous measures rather than thoracotomy and removal of glands in the early stage has been successful in 41 out of the 51 children.

We have now had the opportunity of observing these children over a long period and, except in cases of obstruction of the trachea or large bronchi requiring urgent removal of caseous glands, the policy of maintaining an expectant attitude seems justified. It may be argued that in the seven children in whom lobectomy became necessary, surgical removal of caseating glands would have resulted in re-expansion of the lung and its return to normal, but, with our present knowledge, it has not proved possible to predict which of the lesions will recover spontaneously and which will eventually require operation.

\section{SUMMARY}

This paper reviews 51 cases of primary pulmonary tuberculosis associated with collapse or consolidation leading to a reduction in lung volume.

The good results obtained initially by conservative management and borne out by the children's health during the long follow-up period support our view that surgical treatment during the early stage of the disease is not generally necessary.

Special reference is made to the seven patients requiring surgical treatment and to the histology of the resected specimens: in only one of the six examined was there any evidence of caseous disease.

We are much indebted to Dr. W. E. Lloyd, the senior physician in charge of the children's contact clinic, for the inclusion of children who were under his care, and to Sir Russell Brock, Mr. W. P. Cleland, Mr. O. S. Tubbs, and Sir Clement Price Thomas, who operated on our cases. Much of the follow-up work was possible only by the co-operation of the many physicians in charge of chest clinics who sent reports on the children now in their areas. Dr. George Simon helped us with radiological interpretation, and we are greatly indebted to Mrs. Hulme, secretary of the children's contact clinic, for her invaluable assistance over many years. The photographs were prepared by Mr. A. Curd in the photographic department of the Brompton Hospital.

\section{REFERENCES}

Adams, W. E., Hrdina, L., and Dostal, L. E. (1935). J. thorac. Surg. 4, 377.

Bentley, F. J., Grzybowski, S., and Beniamin, B. (1954). Tuberculosis in Childhood and Adolescence, p. 175. N.A.P.T., London.

Brock, R. C., Cann, R. J., and Dickinson, J. R. (1937). Guv's Hosp. Rep., 87, 295.

Cameron, J. K., Hay, J. D., and Temple, L. J. (1957). Thorax, $12,333$. Eliasberg, H., and Neuland, W. (1920). Jb. Kinderheilk., 93, 88.

Gee, S. (1877). St Bart's Hosp. Rep., 13, 63.

Görgenyi-Göttche, O., and Kassay, D. (1947). Amer. J. Dis. Child., 74, 166.

Hayward, J., and Reid, L. (1952). Thorax, 7, 98

Hutchison, J. H. (1949). Quart. J. Med., n.s., 18, 21.

Jacobs, J. (1958). Brit. J. clin. Pract.. 12, 778.

Jones, E. M., Rafferty, T. N., and Willis, H. S. (1942). Amer. Rev. Tuberc. 46,392 .

Kent, E. M. (1942). Ibid., 46, 524.

Lincoln, E. M., Harris, L. C., Bovornkitti, S., and Cal retero, R. W. (1958). Ibid., 77, 39 .

Macpherson, A. M. C., and Luiwyche, V. Ursula (1950). Thorax, 5, 1

Morlock, H.V., and Pinchin, A. J. S. (1933). Lancet, 1, 1114.

Oppenheimer, E. H. (1935). Bull. Johns Hopk. Hosp., 57, 247.

Rich, A. R. (1951). The Pathogenesis of Tuberculosis, 2 nd ed., p. 862. Thomas, Springfield, Illinois.

Roberts, J. C., and Blair, L. G. (1950). Lancet, 1, 386.

Seal, R. M. E. (1958). Brit. J. clin. Pract., 12, 769.

Van Allen, C. M., and Jung, T. S. (1931). J. thorac. Surg., 1, 3. 